\title{
Valores Humanos e Significado do Dinheiro: Um Estudo Correlacional
}

\author{
Iani Dias Lauer-Leite \\ Universidade Federal do Oeste do Pará \\ Caranazal, PA, Brasil \\ Celina Maria Colino Magalhães \\ Universidade Federal do Pará \\ Belém, PA, Brasil \\ Rildésia Silva Veloso Gouveia \\ Centro Universitário de João Pessoa \\ João Pessoa, PB, Brasil \\ Deliane Macedo Farias de Sousa \\ Universidade Internacional da Paraíba \\ João Pessoa, PB, Brasil \\ Patrícia Nunes da Fonseca \\ Ana Karla Silva Soares \\ Universidade Federal da Paraíba \\ João Pessoa, PB, Brasil
}

\begin{abstract}
RESUMO
Este estudo teve por objetivo verificar a relação entre os valores humanos e o significado do dinheiro para crianças. Participaram 1.445 estudantes com idade média de 11 anos $(d p=1,09)$, a maioria do sexo masculino (51\%), distribuídos entre as regiões Norte $(n=585)$ e Nordeste $(n=860)$ do Brasil. Estes responderam a Escala de Significado do Dinheiro para Crianças (ESDC), Questionário de Valores Básicos Infantis (QVBI) e questões demográficas. Os resultados indicaram diferenças com relação à variável sexo e a região de moradia. Assim como, correlação entre o fator felicidade e a subfunção realização ( $r=0,28)$; os fatores solidão e altruísmo com a subfunção suprapessoal $(r=0,13$ e 0,26 , respectivamente); e, por fim, o fator exclusão com a subfunção normativa $(r=-0,08)$. Conclui-se que os valores humanos infantis, o sexo e o contexto regional influenciam no significado do dinheiro.
\end{abstract}

Palavras-chave: Valores. Crianças. Psicologia econômica.

\section{ABSTRACT}

\section{Human Values and Meaning of Money: A Correlational Study}

This study aimed to investigate the relationship between human values and meaning of money for children. Participants were 1.445 children, with a mean age of 11 years $(s d=1.09$; range $9-14$ years), mostly male $(51 \%)$, and were from north $(n=585)$ and northeast $(n=860)$ of Brazil. They answered the Meaning of Money for Children Scale (MMCS), the children version of Basic Values Survey (BVS-C) and demographic questions. Results pointed differences related to gender and region where children live, as well as correlation between happiness factor and achievement values $(r=0.28)$; loneliness factor and altruism were correlated with suprapersonal values ( $r=0.13$ and 0.26 , respectively); and exclusion presented correlation with normative values $(\mathrm{r}=-0.08)$. In conclusion. follows that human values of children, gender and regional context influence the meaning of money.

Keywords: Values. Children. Economical psychology.

\section{RESUMEN}

\section{Los Valores Humanos y el Significado del Dinero: Un Estudio Correlacional}

El objetivo de este estudio fue verificar la relación de los valores humanos y el significado del dinero para los niños. Participaron 1.445 estudiantes, la mayoría varones $(51 \%)$, con un promedio de edad de 11 años (DT=1,09), repartidos entre las regiones Norte $(n=585)$ y Nordeste $(n=860)$ de Brasil. Éstos cumplimentaron la Escala de Significado del Dinero para Niños (ESDC) y el Cuestionario de Valores Básicos Infantil (CVBI), además de preguntas demográficas. Los resultados mostraron correlaciones directas y estadísticamente significativas entre felicidad y valores de realización $(r=0,28)$, solitud y altruismo con valores suprapersonal, $(r=0,13$ y 0,26 , respectivamente), y, finalmente, el factor con la exclusión con la subfuncion normativa $(r=-0,08)$. De este estudio se concluyó que los valores humanos, el sexo y la región influyen en el sentido del dinero para los niños.

Palabras clave: Valores. Niños. Psicología económica. 


\section{INTRODUÇÃO}

Ao longo da história, o dinheiro vem ocupando um lugar de destaque na vida dos indivíduos, das instituições e das nações, especialmente por ser um instrumento de mediação que possibilita a satisfação das necessidades humanas, do desenvolvimento tecnológico, econômico e social.

O mundo configura-se em torno do dinheiro e é através dele que ocorrem as operações comerciais nacionais e internacionais. Todavia, é a cultura a principal responsável em produzir significado e importância para o dinheiro (Benedict, 1934), o qual dependerá do período e do contexto histórico de uma determinada sociedade.

Nos países capitalistas, o elemento central da economia é o capital, dinheiro investido no processo produtivo com o objetivo de obter lucro. Nestas sociedades, o mercado desenvolve-se em função das necessidades das pessoas que estimulam a produção, a circulação e o consumo dos produtos (Figueiredo, 2010).

Consoante a sua importância no cenário mundial, o dinheiro tem sido estudado por diferentes áreas do conhecimento, a saber: a Economia, que o vê como uma commodity (algo tangível, que tem valor em si mesmo e que pode ser consumido, independente da situação financeira do mercado); a Antropologia, que foca o interesse nos rituais que o envolvem; e a Sociologia e a Psicologia, que, de forma similar, focam seus estudos nos significados simbólicos do dinheiro.

Psicólogos têm estudado o dinheiro sob diferentes perspectivas, tais como: o significado do pagamento (Thierry, 1992), o dinheiro na relação terapêutica (Barth, 2001), o dinheiro e os valores individuais (Moreira, 2000), o dinheiro e o processo de envelhecimento (Beckmann, 2003) e as escalas de significado do dinheiro (Wernimont; Fitzpatrick, 1972; Tang, 1992; Moreira, 2000).

O crescente interesse dos psicólogos em entender o comportamento econômico fez surgir uma área de estudo denominada Psicologia Econômica. Esta objetiva analisar como a economia afeta o comportamento dos indivíduos e como este, por sua vez, afeta a economia (Denegri, 2000). Van Raaij (1999) definiu três domínios em Psicologia Econômica: A Micropsicologia Econômica, a Macropsicologia Econômica e a Economia Psicológica.

No domínio da Micropsicologia Econômica é estudado o comportamento econômico, seus antecedentes e conseqüentes, no nível individual e no nível agregado. Alguns assuntos estudados são: desemprego, pobreza, impostos, comportamentos individuais de guardar, gastar, crédito, dentre outros.

A Macropsicologia Econômica estuda os fatores psicológicos presentes na economia como, por exemplo, a confiança, o crédito e as expectativas quanto às instituições econômicas, o sistema monetário e a política econômica. Nela são abordados assuntos como renda total, consumo total e poupança total.

$\mathrm{Na}$ Economia Psicológica, algumas suposições básicas da teoria econômica são questionadas, e as teorias e conceitos psicológicos substituem as teorias e conceitos econômicos tradicionais. Também há uma preocupação em focalizar a metodologia psicológica aplicada à economia, especialmente na coleta de dados. Dentro dessa delimitação, vários são os temas de interesse, dentre eles (Lewis, Webley e Furnhan, 1995): a socialização econômica, a psicologia do dinheiro, os problemas sociais, a moral e o mercado, as mudanças e a transição econômica.

Conforme o exposto, o significado do dinheiro está contemplado dentro dos interesses da Psicologia Econômica, especificamente na psicologia do dinheiro que busca entender como as pessoas desenvolvem o significado do dinheiro, quais são eles e como as propriedades físicas do dinheiro interferem no comportamento dos indivíduos.

Furnham (1996), Távora (2003) e Moreira (2000) mostram que existem diferentes significados atribuídos ao dinheiro, e estes são influenciados por variáveis tais como: sociodemográficas (sexo, idade, nível educacional), de personalidade (obsessividade, ansiedade), do trabalho (salário, atitudes conservadoras) e valorativas (tipos motivacionais).

No entanto, os significados não são formados apenas quando os indivíduos se tornam adultos; ao contrário, eles vão sendo formados ainda na infância, sob influência dos pais, da escola, do ambiente em que vivem, das crenças e dos valores presentes na cultura. Nesse sentido, tendo em vista a influência que os valores apresentam na predição de vários comportamentos, considera-se relevante estudar a influência dos valores humanos no significado simbólico que as crianças atribuem a uma variável subjetiva, tal como o dinheiro.

Considerando a necessidade científica e social de privilegiar essa temática, especificamente no público infantil, faz-se justificável analisar a relação entre o significado do dinheiro e os valores na infância; partindo de um modelo teórico parcimonioso, integrador e que se demonstra empiricamente adequado no contexto brasileiro, denominada teoria funcionalista dos valores humanos (Gouveia, 2003; Gouveia et al., 2011; Gouveia; Milfont; Fischer; Santos, 2008). 


\section{A TEORIA FUNCIONALISTA DOS VALORES HUMANOS}

Os valores humanos são estudados desde diferentes perspectivas. Na literatura, referências sobre o tema são encontradas em diferentes áreas do conhecimento, como a filosofia, antropologia, sociologia e psicologia (Gouveia, 2003; Ros, 2006).

$\mathrm{Na}$ psicologia, mais especificamente, existem diversas teorias sobre prioridades axiológicas, provavelmente as mais conhecidas são as de Ronald Inglehart e Shalom H. Schwartz. No entanto, mesmo sem deixar de reconhecer as contribuições dos modelos existentes sobre valores, Gouveia et al., $(1998,2003 ; 2008 ; 2009 ; 2010 ; 2011)$ propõe um modelo alternativo, a Teoria Funcionalista dos Valores Humanos, que se mostra mais parcimoniosa e que tem apresentado padrões de adequabilidade satisfatórios, principalmente, quanto aos estudos direcionados à amostra de infantes no contexto brasileiro (Andrade, 2002; Gouveia et al., 2011).

Segundo Gouveia et al. (2008), os valores são critérios de orientação que guiam as ações humanas e expressão suas necessidades básicas. Esta concepção inclui três suposições teóricas: (1) assume a natureza benevolente do ser humano; (2) os valores são representações cognitivas das necessidades individuais, demandas da sociedade e institucionais, que restringem os impulsos pessoais e asseguram um ambiente estável e seguro; e (3) todos os valores são terminais, ou seja, expressam um propósito em si, sendo definidos como substantivos. A partir dessas análises, o autor identifica duas funções consensuais dos valores (Gouveia, 2003; Gouveia et al., 2011), relacionadas à sua definição: (a) guiam as ações humanas (tipo de orientação;
Rokeach, 1973; Schwartz, 1992) e (B) representam suas necessidades (tipo de motivador; Inglehart, 1977; Maslow, 1954).

Gouveia et al. (2008) parte da concepção de que os indivíduos enfatizam a si ou o grupo como uma unidade central de sobrevivência, de maneira que seus comportamentos são guiados por orientações pessoais ou sociais, respectivamente. No entanto, os autores também defendem a existência de um tipo de valor que se apresenta entre os dois os outros dois tipos de orientação, sendo denominado de centrais. Neste sentido, a função dos valores como princípios que guiam o comportamento dos indivíduos pode ser definida como a dimensão tipo de orientação, dividida em três critérios axiológicos: pessoais, central e social.

Apesar de não haver uma correspondência perfeita entre as necessidades e valores, Gouveia et al. (2009; 2010) consideram possível concebê-los como expressão das necessidades, classificando-os como materialistas (pragmáticos) ou idealistas (humanitários).

As duas dimensões funcionais dos valores formam dois eixos principais. $\mathrm{O}$ eixo horizontal corresponde ao tipo de orientação e o vertical ao tipo de motivador. O cruzamento destes eixos (social, central e pessoal / materialista e humanitário) geram seis subfunções, distribuídas de forma equitativa entre os critérios de orientação social (interativa e normativa), central (suprapessoal e existência) e pessoal (experimentação e realização) e entre os tipos motivadores Idealista (interativa, suprapessoal e experimentação) e Materialista (normativa, existência e realização). A seguir, será apresentado um esquema desta estrutura e a descrição de cada subfunção, considerando o tipo de orientação e o tipo motivador.

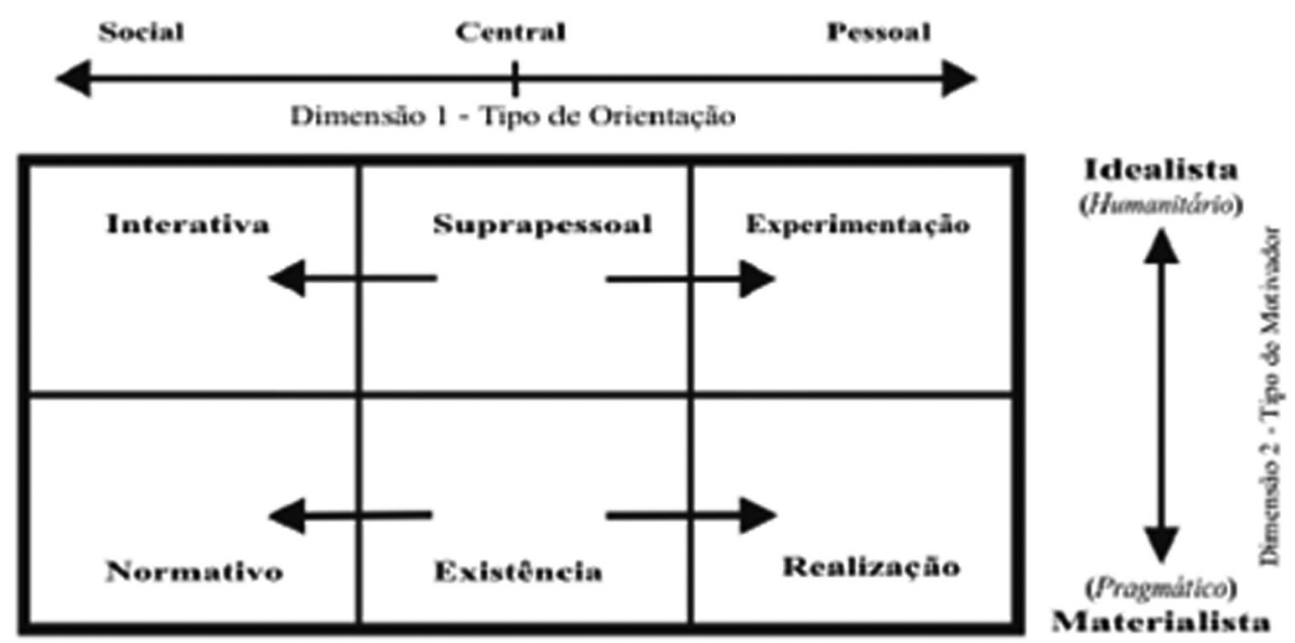

Figura 1. Facetas, dimensões e subfunções dos valores básicos. 
As pessoas que adotam os Valores Pessoais procuram alcançar metas pessoais, garantia de benefícios próprios e condições propícias para o alcance de seus objetivos. Esse critério de orientação é subdividido em:

Experimentação (emoção, prazer e sexualidade). Os indivíduos pautados nesta subfunção são representados pelo motivador idealista (humanitário), com uma orientação pessoal. Seus valores favorecem a promoção de mudança e inovação na estrutura das organizações sociais. As pessoas que adotam os valores de experimentação não se conformam facilmente com regras sociais, não sendo orientados, a longo prazo, a buscarem metas fixas ou materiais.

Realização (êxito, poder e prestígio). É constituído por valores representativos do motivador materialista com orientação pessoal. As pessoas orientadas por tais valores focalizam realizações materiais e buscam a praticidade em decisões e comportamentos. Valores de realização são mais apreciados por jovens adultos em fase produtiva, ou indivíduos educados em contextos disciplinares e formais.

As pessoas compatíveis com os Valores Sociais demonstram priorizar a convivência social. Estão relacionados aos interesses coletivos e à importância de ser aceito e integrado ao grupo, tentando manter a harmonia entre todos. São subdivididos em:

Normativa (obediência, religiosidade e tradição). Apresentam uma orientação social direcionada as regras sociais, e um motivador materialista que reflete a importância de preservar a cultura e as normas sociais. Seus valores enfatizam a vida social, a estabilidade grupal e o respeito por símbolos e padrões culturais que prevaleceram durante anos; a obediência é valorizada acima de qualquer coisa. Geralmente, as pessoas mais velhas são guiadas por valores desta subfunção.

Interativa (afetividade, apoio social e convivência). São representantes das necessidades de pertença, amor e afiliação, promovendo o estabelecimento e a manutenção das relações interpessoais por parte do indivíduo. Representa o motivador idealista (humanitário) com orientação social, sendo características de pessoas mais jovens e orientadas para relações íntimas estáveis.

Os indivíduos compatíveis com os Valores Centrais são aqueles que servem a interesses mistos e localizam-se entre os valores pessoais e sociais.

Existência (estabilidade pessoal, saúde e sobrevivência). São compatíveis com as orientações sociais e pessoais e estão localizados no motivador materialista; o propósito principal é assegurar as condições fisiológicas mais básicas (beber, dormir, comer) e a necessidade de segurança, principalmente a de sobrevivência biológica e psicológica. Indivíduos que foram socializados ou habitam contextos de escassez econômica são mais comumente endossados por esse valor.

Suprapessoais (beleza, conhecimento e maturidade). Os valores desta subfunção apresentam orientação central e motivador humanitário. Seus valores representam as necessidades estéticas, de cognição e de autorrealização. Esses valores indicam a relevância atribuída a ideias abstratas, são endossadas por pessoas que pensam de maneira mais geral e ampla, e que tomam decisão e se comportam baseados em critérios universais.

As versões do Questionário de Valores Humanos (QVB) que contemplam os valores supracitados foram desenvolvidas para mensuração em populações de adolescentes e adultos. Não obstante, para o presente estudo, empregou-se uma versão adaptada para amostra composta por infantes. Nesta, alguns valores que não fazem parte do quotidiano das crianças foram substituídos (por exemplo, (1) Sexualidade. Ter relações sexuais, obter prazer sexual; deu lugar a Estimulação. Sempre fazer algo diferente, não estar parado(a); participar em todas as brincadeiras que puder; e estar sempre se divertindo, buscando o que fazer; bem como substitui-se na subfunção suprapessoal os valores maturidade e beleza por igualdade e artes, respectivamente).

Em resumo, na literatura são apontadas as influências que os valores exercem sobre atitudes, crenças, comportamento e construtos comumente estudados na área das ciências humanas em geral. Assim, partindo da concepção de que os valores dos indivíduos se relacionam com o significado do dinheiro, foi realizado o presente estudo que teve como objetivo principal conhecer os correlatos valorativos das crianças frente ao significado atribuído ao dinheiro.

\section{MÉTODO}

\subsection{Participantes}

Contou-se com a participação de 1.445 estudantes, com idade média de 11 anos $(d p=1,09$; amplitude de 9 a 14 anos), a maioria do sexo masculino (51\%), distribuídos entre as regiões Norte $(n=585)$ e Nordeste $(\mathrm{n}=860)$ do Brasil. Tratou-se de uma amostra de conveniência (não probabilística), tendo participado aqueles que, presentes em sala de aula, decidiram colaborar voluntariamente.

\subsection{Instrumentos}

Os participantes receberam um livreto contendo perguntas de natureza demográfica (idade, sexo e nível educacional), disponibilizadas ao final, e os dois seguintes instrumentos: 
Questionário dos Valores Básicos Infantil (QVB-I). Compreende um instrumento tipo lápis e papel, de autoinforme, que tomou como referência a medida usada por Andrade (2002), que foi criada a partir daquela elaborada para adultos por Gouveia (1998; 2003). A versão atual se compõe de 18 itens (por exemplo, Saúde. Não ficar doente; estar sempre animado/a, com vontade de brincar; e evitar fazer coisas que prejudiquem a saúde; Artes. Ir a exposições de quadros e esculturas; ouvir música, ir ao teatro ou ao cinema; e aprender a desenhar e pintar), igualmente distribuídos nas seis subfunções. Os participantes devem indicar a importância que cada valor tem em sua vida, de acordo com escala de cinco pontos, representados por feições de bonecos e números, variando de 1 (Nenhuma importância) a 5 (Máxima importância). Os valores justiça social, vencer, honestidade e autodireção, presentes no instrumento de Andrade (2002), foram substituídos por igualdade, êxito, afetividade e prestígio, respectivamente.

Escala de Significado do Dinheiro para Criança (ESDC). Esta versão foi elaborada a partir da medida proposta por Moreira (2000), em uma amostra constituída por adultos. A versão utilizada no presente estudo é composta por 41 itens (por exemplo, Dinheiro significa sobrevivência, é difícil sobreviver sem dinheiro; Quando as pessoas têm dinheiro no bolso ficam mais alegres), sendo distribuídos em quatro fatores: altruísmo, solidão, exclusão e felicidade. Tais itens são respondidos em escala representada por feições de bonecos que variam de Discordo muito a Concordo muito.

\subsection{Procedimento}

Primeiramente, contataram-se os colaboradores nas capitais nordestinas e nortistas participantes e, em seguida, os mesmos mantiveram contato com diretores de instituições de ensino procurando obter permissão para a aplicação dos questionários. Explicaram-se os objetivos da pesquisa e, após a assinatura do termo de responsabilidade autorizando a participação dos estudantes de suas respectivas instituições de ensino, combinou-se o melhor horário para realização da coleta de dados. Embora a aplicação tenha sido realizada em ambiente coletivo de sala de aula, as respostas foram dadas individualmente. Enfatizou-se o caráter voluntário e a garantia do anonimato e sigilo da participação. Foram necessários, em média, 40 minutos para concluir esta atividade.

\subsection{Análise de dados}

O SPSS (versão 15) foi utilizado para tabular e analisar os dados. Calcularam-se, além de estatísticas descritivas (frequência, média e desvio padrão), coeficientes de correlações $r$ de Pearson, testes $t$, Manova e análises de regressão hierárquicas.

\section{RESULTADOS}

Os resultados deste estudo são apresentados em duas partes principais. Inicialmente, calcularam-se estatísticas descritivas sobre o significado do dinheiro e as características demográficas dos participantes. Posteriormente, correlacionaram-se as pontuações das subfunções valorativas com aquelas dos fatores correspondentes ao significado simbólico do dinheiro atribuído pelos participantes. Tais resultados são descritos a seguir.

\subsection{Significado do dinheiro e características demográficas}

De acordo com os resultados, o dinheiro, no geral, apresentou para os jovens investigados, principalmente, o significado simbólico que evidencia o altruísmo $(m=3,80, d p=0,77)$, isto é, as crianças e os adolescentes ouvidos indicaram que ele deve ser fonte de auxílio a outras pessoas. O segundo fator com média mais alta foi solidão $(m=3,64, d p=0,74)$, sugerindo que o dinheiro é percebido como causador de conflitos e distanciamento entre as pessoas. Ele também foi concebido como causa de exclusão $(m=2,75, d p=0,90)$ daqueles que não o possuem, sugerindo uma hierarquização em termos de possuí-lo ou não. Por último, o dinheiro significou felicidade $(m=2,73, d p=0,77)$, entendendo-se por este construto elementos variados (e.g., poder, relacionamentos e ausência de conflitos) $[$ Lambda de Wilks $=0,41 ; \mathrm{F}(3,1096)=514,02$, $p<0,001]$.

Procedeu-se uma MANOVA considerando o sexo e a região de moradia (norte e nordeste) como variáveis interssujeitos e os quatro componentes da escala de significado atribuído ao dinheiro como variáveis-critério (dependentes). A variável sexo apresentou efeito principal [Lambda de Wilks $=0,97$, $\mathrm{F}(4,1092)=7,46, p<0,001, \square=0,03]$, tendo os testes univariados indicado diferença apenas entre os fatores felicidade $(\mathrm{F}(1,1095)=13,85, p=0,001) \mathrm{e}$ altruísmo $(\mathrm{F}(1,1095)=1,73, p=0,001)$. Por sua vez, a variável região de moradia apresentou efeito principal [Lambda de Wilks=0,96, F(4, 1092) $=11,58, p<0,001$, $\square=0,04]$, cujos resultados indicaram haver diferença entre os componentes: felicidade $(\mathrm{F}(1,1095)=14,16$, $p=0,001)$, altruísmo $(\mathrm{F}(1,1095)=4,83, p=0,03) \mathrm{e}$ exclusão $(\mathrm{F}(1,1095)=12,81, p=0,001)$.

Especificamente, as meninas apresentaram maior média nos fatores altruísmo $(m=3,89 ; d p=0,73)$, 
exclusão $(m=2,75 ; d p=0,92)$ e solidão $(m=3,65$; $d p=0,74)$, quando comparadas aos meninos [altruísmo $(m=3,72 ; d p=0,81)$, exclusão $(m=2,73 ; d p=0,89)$ e solidão $(m=3,60 ; d p=0,75)]$, com exceção do fator felicidade, em que os meninos $(m=2,81 ; d p=0,80)$ apresentaram pontuação superior $(m=2,63 ; d p=0,76)$. Por outro lado, tendo em consideração a região dos participantes, as crianças nortistas obtiveram maior média nos fatores felicidade $(m=2,83 ; d p=0,76)$ e altruísmo $(m=3,86 ; d p=0,79)$, enquanto os participantes nordestinos expressaram maiores média nos fatores solidão $(m=3,63 ; d p=0,73)$ e exclusão $(m=2,83, d p=0,88)$. Foram observadas diferenças nos significados atribuídos ao dinheiro, por meninos e meninas. Mediante o teste $\mathrm{t}(p<0,01)$, verificou-se que para os meninos o dinheiro é fonte de felicidade $(m=2,83)$, mais que para meninas $(m=2,64)$. Por outro lado, as meninas mostraram pensamentos mais altruístas quanto ao dinheiro $(m=2,76)$ do que os meninos $(m=2,73)$. Diferenças também foram encontradas quanto ao local de moradia. Mediante o teste $\mathrm{t}(p<0,01)$, verificou-se que de forma geral, crianças nortistas acreditaram mais que o dinheiro traz felicidade $(m=2,86)$ do que crianças nordestinas $(m=2,65)$. Estas, por sua vez, significaram mais o dinheiro como fonte de exclusão $(m=2,83)$, do que crianças nortistas $(m=2,62)$.

Os resultados das análises por cidade confirmaram os resultados por região, e foram realizados através da ANOVA. Foram encontradas diferenças em três fatores. Para $\mathrm{o}$ fator felicidade $(p<0,05)$, houve diferenças entre as quatro cidades pesquisadas.
Crianças manauaras $(m=2,82)$ e belenenses $(m=2,90)$ acreditaram que o dinheiro é sinônimo de felicidade mais do que soteropolitanos $(m=2,74)$ e moradores pessoenses $(m=2,49)$. Não houve diferenças entre manauaras e belenenses. Já para os nordestinos, verificou-se diferença entre soteropolitanos $(m=2,74)$ e pessoenses $(m=2,49)$.

No fator altruísmo, só houve diferenças $(p<0,05)$ entre manauaras $(m=3,94)$ e soteropolitanos $(m=3,76)$. Quanto ao fator exclusão $(p<0,05)$, observou-se que manauaras $(m=2,36)$ acreditaram menos que o dinheiro promove a exclusão, em relação a belenenses $(m=2,84)$, soteropolitanos $(m=2,89)$ e pessoenses $(m=2,71)$. Já a diferença entre soteropolitanos $(m=2,89)$ e pessoenses $(m=2,71)$ mostrou que os primeiros priorizaram mais esse fator que os últimos.

\subsection{Correlatos valorativos do significado do dinheiro}

Nesta oportunidade, procurou-se verificar quais as prioridades valorativas dos participantes distinguindo-os quanto ao local de moradia (Manaus, Belém, Salvador e João Pessoa). A representação do perfil valorativo de cada grupo pode ser observada na Figura 2.

Procurou-se calcular a pontuação total média para cada uma das subfunções, como seguem em ordem decrescente: existência $(\mathrm{m}=4,55, \mathrm{dp}=0,52)$, interativa $(\mathrm{m}=4,52, \mathrm{dp}=0,56)$, normativa $(\mathrm{m}=4,33, \mathrm{dp}=0,64)$, experimentação $(\mathrm{m}=4,11, \mathrm{dp}=0,69)$, suprapessoal $(m=4,03, d p=0,64)$ e realização $(m=2,84, d p=0,88)$ [Lambda de Wilks $=0,23 ; \mathrm{F}(5,1298)=890,12, p<0,001]$.

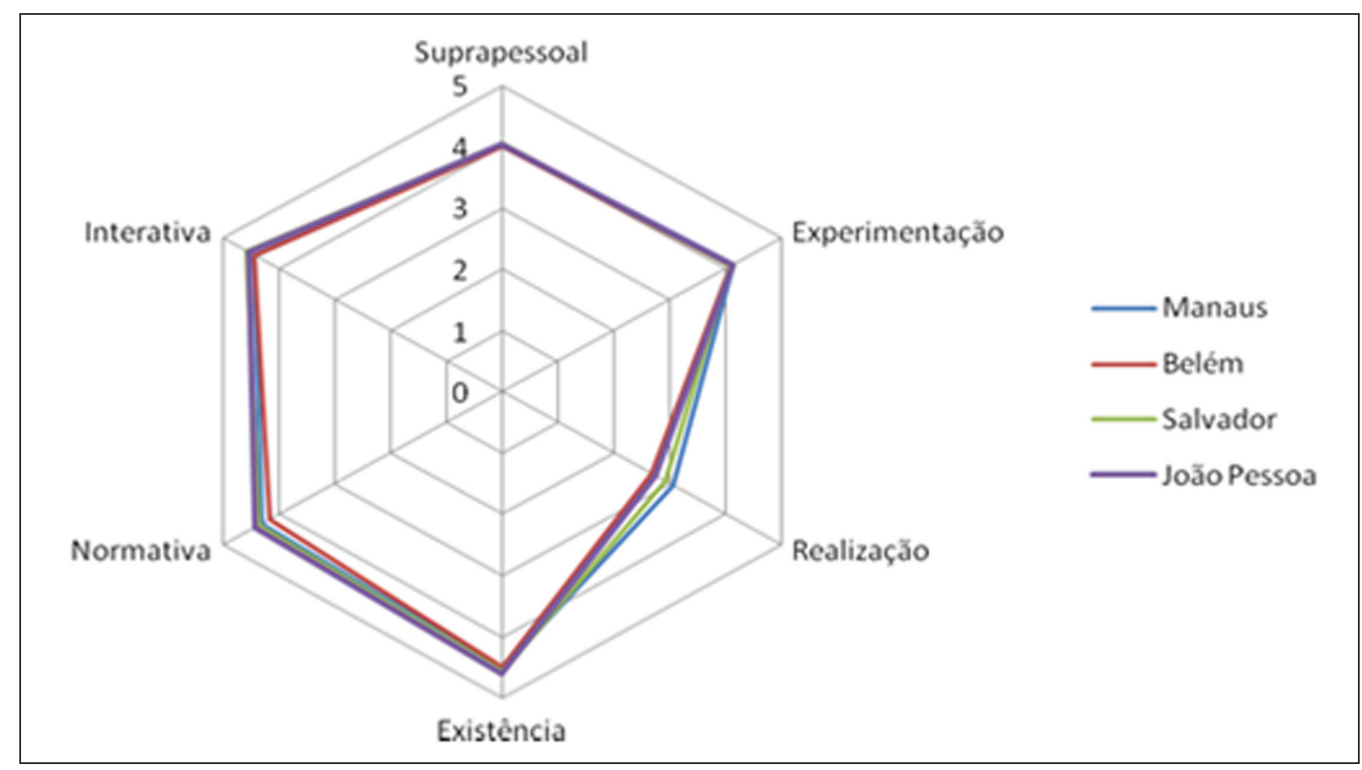

Figura 2. Prioridades valorativas dos participantes por cidade 
Foram calculadas correlações ( $r$ de Pearson; teste uni-caudal) entre os quatro fatores da medida de significado do dinheiro e as seis subfunções valorativas. Os resultados podem ser vistos na Tabela 1.

Como pode ser observado, o fator felicidade se correlacionou mais fortemente com a subfunção realização ( $r=0,28)$; solidão e, principalmente, altruísmo, o fizeram com a subfunção suprapessoal $(r=0,13 \mathrm{e}$ 0,26 , respectivamente); e, por fim, exclusão apresentou maior associação com a subfunção normativa $(r=-0,08)$.

Conhecido que os fatores de significado do dinheiro se diferenciaram em função das variáveis sexo e região de moradia, além de estarem correlacionados com os valores humanos, pretendeu-se averiguar em que medida estes últimos construtos podem explicar a variação em tais significados, além do que poderia ser creditado a variáveis demográficas. Neste sentido, realizaram-se análises de regressão hierárquicas, tendo as variáveis gênero e região (Bloco 1) e as subfunções valorativas (Bloco 2) como preditoras de cada um dos quatro fatores de significado do dinheiro. Os resultados são apresentados separadamente a seguir.

\subsubsection{Felicidade}

Como pode ser observado na Tabela 2, as variáveis gênero e região, agrupadas no Bloco 1, contribuíram com 2,9\% da variância explicada. Com a entrada das variáveis do Bloco 2, a explicação das pontuações neste fator aumentou para $16 \%$, havendo um acréscimo de 13,1\% na variância ( $R^{2}$ Mudança).

Gênero e região de moradia foram preditores do significado do dinheiro como felicidade no Bloco 1. Verificou-se que para os meninos o dinheiro é fonte de felicidade $(\mathrm{m}=2,83)$ mais do que para as meninas ( $m=2,64)(t=4,46, p<0,001)$; também foi observado que os participantes nortistas acreditaram mais que o dinheiro traz felicidade $(m=2,86)$ do que aqueles nordestinos $(m=2,65)(t=4,86, p<0,001)$.

Quanto aos valores básicos, todas as subfunções psicossociais foram preditoras Explicando, em conjunto, $15 \%$ da variância. Tais resultados evidenciam que crianças que priorizam valores de natureza pessoal como estimulação, emoção, êxito e poder, vêem o dinheiro como sinônimo de felicidade. Crianças que valoram sobrevivência, estabilidade e saúde também acreditam que o dinheiro é fonte de felicidade, numa ênfase menor.

Como preditores com beta negativo entraram as funções interativa, suprapessoal e normativa. Crianças que apresentaram altos escores em valores como afetividade, apoio e convivência não significam o dinheiro como felicidade, assim como aquelas que valoram a função suprapessoal, que representa valores como conhecimento, igualdade e artes. Por fim, os valores de tradição, religiosidade e obediência apresentaram Betas negativos, significando que indivíduos que pontuam mais alto na função psicossocial normativa não vêem o dinheiro como felicidade.

TABELA 1

Correlação de fatores de significado do dinheiro com subfunções valorativas

\begin{tabular}{lcccc}
\hline \multicolumn{1}{c}{$\begin{array}{c}\text { Subfunções } \\
\text { valorativas }\end{array}$} & \multicolumn{4}{c}{ Fatores de Significado do Dinheiro } \\
\cline { 2 - 5 } Experimentação & $0,13^{* *}$ & Solidão & Altruísmo & Exclusão \\
Realização & $0,28^{* *}$ & $0,08^{* *}$ & $0,12^{* *}$ & 0,01 \\
Existência & $-0,03$ & 0,03 & $-0,07^{*}$ & $0,06^{*}$ \\
Suprapessoal & $-0,13^{* *}$ & $0,10^{* *}$ & $0,16^{* *}$ & $-0,01$ \\
Interativa & $-0,11^{* *}$ & $0,13^{* *}$ & $0,26^{* *}$ & $-0,01$ \\
Normativa & $-0,23^{* *}$ & $0,11^{* *}$ & $0,23^{* *}$ & 0,02 \\
\hline
\end{tabular}

$* p<0,05 ; * * p<0,01$ (teste uni-caudal).

TABELA 2

Modelos de análises de regressão para o fator felicidade

\begin{tabular}{clcccc}
\hline \multicolumn{1}{c}{ Modelos } & \multicolumn{1}{c}{ Preditores } & Beta & $R^{2}$ & $R^{2}$ ajustado & $R^{2}$ Mudança \\
\hline Bloco 1 & Gênero & $-0,112^{* *}$ & $0,029^{* *}$ & $0,027^{* *}$ & $0,029^{* *}$ \\
& Região & $-0,117^{* *}$ & & & $0,131^{* *}$ \\
Bloco 2 & Experimentação & $0,125^{* *}$ & $0,160^{* *}$ & $0,154^{* *}$ & \\
& Realização & $0,234^{* *}$ & & & \\
& Existência & $0,067^{*}$ & & & \\
& Suprapessoal & $-0,127^{* *}$ & & & \\
& Interativa & $-0,028$ & & & \\
& Normativa & $-0,173^{* *}$ & & & \\
\end{tabular}

$* p<0,05 ; * * p<0,01$. 


\subsubsection{Solidão}

Para este fator nenhuma variável do bloco 1 foi preditora. No bloco 2 apenas a função suprapessoal foi preditora e explicou $2,8 \%$ da variância.

$\mathrm{O}$ beta positivo para a variável suprapessoal indica que esta variável contribuiu com $8,8 \%$ na predição para este fator, significando que crianças que priorizam valores de conhecimento, igualdade e artes entendem que o dinheiro pode ser fonte de solidão.

\subsubsection{Altruísmo}

Nesse fator o bloco 1 contribuiu com $1,7 \%$ para a variância explicada. A análise do $R^{2}$ evidencia que o bloco 2 fez esse valor aumentar para $14,1 \%$, havendo, portanto, um acréscimo de $12,4 \%$ na variância explicada.

No bloco 1, gênero foi preditor positivo. Mediante teste t $(p<0,01)$ foi observado que meninas $(m=2,76)$ significaram mais o dinheiro como altruísmo do que meninos $(m=2,73)$.

No segundo bloco as funções suprapessoal, interativa e normativa apresentaram beta positivo, indicando que crianças que priorizam valores de cunho social, como aqueles voltados para os relacionamentos interpessoais (afetividade e convivência) e a conservação da ordem social (tradição, obediência) acreditam que o dinheiro significa altruísmo. Também pensam assim as crianças que valorizam a função suprapessoal, representada por valores como conhecimento, igualdade e artes.

\subsubsection{Exclusão}

Para esse fator, apenas a variável Região foi preditora no bloco 1 , que apresentou variância explicada de apenas $1 \%$. Com a entrada do bloco 2 a variância subiu para $2,4 \%$.

TABELA 3

Modelos de análises de regressão para o fator solidão

\begin{tabular}{llcccc}
\hline \multicolumn{1}{c}{ Modelos } & \multicolumn{1}{c}{ Preditores } & Beta & $R^{2}$ & $R^{2}$ ajustado & $R^{2}$ Mudança \\
\hline Bloco 1 & Gênero & 0,049 & 0,00 & 0,001 & 0,002 \\
& Região & $-0,007$ & & & $0,026^{* *}$ \\
Bloco 2 & Experimentação & 0,036 & $0,028^{* *}$ & $0,022^{* *}$ & \\
& Realização & $-0,038$ & & & \\
& Existência & 0,049 & & & \\
& Suprapessoal & $0,088^{* *}$ & & & \\
& Interativa & 0,061 & & & \\
& Normativa & $-0,014$ & & &
\end{tabular}

Notas: $* p<0,05 ; * * p<0,01$.

TABELA 4

Modelos de análises de regressão para o fator altruísmo

\begin{tabular}{clcccc}
\hline \multicolumn{1}{c}{ Modelos } & \multicolumn{1}{c}{ Preditores } & Beta & $R^{2}$ & $R^{2}$ ajustado & $R^{2}$ Mudança \\
\hline Bloco 1 & Gênero & $0,113^{* *}$ & $0,017^{* *}$ & $0,015^{* *}$ & $0,017^{* *}$ \\
& Região & $-0,074$ & & & $0,124^{* *}$ \\
& Experimentação & 0,052 & $0,141^{* *}$ & $0,135^{* *}$ & \\
& Realização & $-0,076^{* *}$ & & & \\
& Existência & 0,000 & & \\
& Suprapessoal & $0,127^{* *}$ & & \\
& Interativa & $0,93 * *$ & & \\
& Normativa & $0,221^{* *}$ & & \\
\hline
\end{tabular}

${ }^{*} p<0,05 ; * * p<0,01$.

TABELA 5

Modelos de análises de regressão para o fator exclusão

\begin{tabular}{llccc}
\hline \multicolumn{1}{c}{ Modelos } & \multicolumn{1}{c}{ Preditores } & Beta & $R^{2}$ & $R^{2}$ ajustado \\
\hline Bloco 1 & Gênero & 0,010 & 0,010 & 0,009 \\
& Região & $0,100^{* *}$ & & 0,010 \\
Bloco 2 & Experimentação & $-0,020$ & 0,024 & 0,017 \\
& Realização & $0,060^{*}$ & & \\
& Existência & 0,011 & \\
& Suprapessoal & 0,003 & & \\
& Interativa & 0,029 & & \\
& Normativa & $-0,106^{* *}$ & \\
\hline
\end{tabular}

$* p<0,05: * * p<0,01$. 
A variável Região permaneceu com a entrada das variáveis do bloco 2. Os resultados indicaram que nordestinos acreditam mais no dinheiro como fonte de exclusão do que nortistas. Quanto aos valores, observou-se que realização contribuiu com $6 \%$ com beta positivo, enquanto a normativa apresentou beta negativo e contribuiu com $10 \%$. Tais resultados indicam que crianças que priorizam valores como poder, prestígio e êxito entendem que o dinheiro pode excluir; ao mesmo tempo, crianças que valoram as normas sociais impostas não acreditam que o dinheiro cause exclusão.

\section{DISCUSSÃO}

O estudo mostrou que o propósito de analisar a relação entre os valores e o significado do dinheiro para as crianças, assim como, averiguar a influência dos valores humanos e das variáveis 1) gênero e 2) região de moradia sobre o significado do dinheiro, foi atendido de forma satisfatória. Assim, os resultados foram interpretados e discutidos tendo como base a ideia de que tanto os valores quanto a região de moradia são parte do contexto de desenvolvimento da criança.

Primeiramente, o significado atribuído ao dinheiro foi de altruísmo para as crianças pesquisadas, sendo, compreendido como fonte de auxílio a outras pessoas. Em seguida, o dinheiro recebeu o significado de solidão, exclusão e por último, felicidade. Quanto aos valores básicos, os resultados indicaram preocupação, primeiramente, com valores de existência, seguidos pelas subfunções interativa, normativa, experimentação, suprapessoal e realização.

Para avaliar o poder preditivo dos valores sobre o significado do dinheiro, foi usada a técnica estatística da análise de regressão. Foram realizadas análises de regressão hierárquicas, entrando no primeiro bloco as variáveis gênero e região de moradia, e no segundo bloco os valores humanos. Os resultados encontrados demonstraram o maior poder preditivo dos valores, sem, contudo, desprezar a contribuição de gênero e região de moradia, para a compreensão dos diferentes significados atribuídos ao dinheiro pelas crianças. A seguir comentam-se os resultados quanto às variáveis pesquisadas.

A variável gênero foi preditora para os fatores felicidade e altruísmo, sendo que meninos consideraram mais o dinheiro como felicidade e meninas pontuaram mais alto em altruísmo. É possível que a relação entre gênero e significado do dinheiro sofra influência das práticas parentais quanto à educação econômica. Cabe relembrar aqui um dos subsistemas do Nicho de Desenvolvimento: as características psicológicas dos pais, que influem nas crenças e práticas de cuidado com os filhos (Super; Harkness, 1986). Essa hipótese é corroborada por um estudo anterior sobre socialização econômica e gênero, realizado por Rinaldi e Giromini (2001), no qual as autoras descobriram que os pais socializam meninos e meninas de maneira diferente.

A variável região apresentou poder de predição sobre felicidade e exclusão. Crianças nortistas analisaram o dinheiro como fonte de felicidade mais que crianças nordestinas, que, por outro lado, apresentaram médias mais altas em exclusão. Esses resultados remetem às similaridades e diferenças, tanto geográficas quanto econômicas, sociais e culturais dessas duas regiões. Como fator comum, norte e nordeste são regiões vistas ainda por muitos como "atrasadas", ainda em desenvolvimento em relação às demais regiões do país. Ambas as regiões compartilham similaridades culturais e de costumes, como preferências musicais, culinária, danças e festas. De fato, percebe-se o povo nortista (Manaus e Belém) e nordestino (Salvador e João Pessoa) como mais aberto e acolhedor. E essa observação é comprovada empiricamente na análise das prioridades valorativas, na qual os valores de cunho interativo como afetividade, apoio e convivência tiveram altos escores.

Em se tratando da situação econômica das duas regiões, ambas passaram por períodos de intensa exploração no passado histórico, sem que esta exploração tivesse trazido melhora significativa para a qualidade de vida dos nativos da região. No entanto, nortistas foram mais agraciados por um clima que propicia maior possibilidade de produzir, o que aumenta as chances de mobilidade econômica e social do povo. Por outro lado, nordestinos lidam com um clima inóspito há um longo tempo, o que contribui para a visão deste como corajoso e sofredor, sobrevivente da seca. Essa visão "romântica" do nordestino não é suficiente para a sua inclusão em alguns círculos, pois, mesmo tendo alcançado mobilidade social, o nordestino ainda carrega o estereótipo da seca. Essa ideia é reforçada diante da análise da priorização dos valores destes, que pontuaram alto em valores relativos à existência, como busca por sobrevivência, estabilidade e saúde.

Em se tratando dos valores como preditores e compreendidos como parte do contexto de desenvolvimento, fortemente presentes na cultura, observou-se que estes influem na formação de conceitos econômicos. Foi demonstrado que os significados do dinheiro são influenciados pelos valores individuais das crianças, ainda que estes valores estejam em formação. Assim, para o fator felicidade foram preditores realização e existência, significando que crianças focadas no cumprimento de metas individuais e na busca por 
novas experiências crêem que o dinheiro pode trazer felicidade, assim como aquelas que estão preocupadas com a sobrevivência e estabilidade. Por outro lado, crianças que valoram mais os relacionamentos interpessoais e valores suprapessoais tendem a não ver o dinheiro como fonte de felicidade. Ao contrário, para estas, o dinheiro deve ser utilizado para fins altruístas, como subsidiar pesquisas em prol da cura de doenças como o câncer e a AIDS, e promover o acesso à cultura para outras crianças.

Os fatores negativos do dinheiro foram solidão e exclusão. Para solidão foram preditores os valores suprapessoais. Por outro lado, crianças que valoram o comportamento normativo, acreditaram que o dinheiro não é fonte de exclusão, provavelmente por entenderem que o objetivo final das normas e tradições é promover a igualdade de direito e oportunidade entre as pessoas.

Conclui-se, portanto, que a existência de relação entre os valores humanos infantis, o gênero e o contexto regional são capazes de influenciar os significados que as crianças atribuem ao dinheiro. Tais dados são pertinentes porque servem, ao mesmo tempo, como base e indicador de estudos futuros sobre os fenômenos psicossociais que envolvem tal relação. Também se mostram úteis porque são fonte de informação para que os pais, a escola, instituições financeiras e mídia possam pensar em estratégias e ações capazes de conscientizar e promover uma educação frente ao dinheiro, o seu significado e uso.

\section{REFERÊNCIAS}

Andrade, P. R. (2002). Correlatos valorativos da preferência por desenhos animados: compreendendo a justificativa da agressão. Dissertação de Mestrado. Departamento de Psicologia, Universidade Federal da Paraíba.

Barth, F. D. (2001). Money as a tool for negotiating separateness and connectedness in the therapeutic relationship. Clinical social work journal, 29(2), 79-93.

Beckmann, A. C. M. (2003). Relação entre eventos afetivos e financeiros a partir da metodologia de eventos significativos na linha de vida de idosos. Trabalho de conclusão de curso não publicado. Universidade Federal do Pará.

Benedict, R. (1934). Padrões de cultura. Lisboa: Livros do Brasil.

Figueiredo, L. V. (2010). Lições de Direito Econômico (3 ${ }^{\mathrm{a}}$ ed.). Rio de Janeiro: Forense.

Furnham, A. (1996). Attitudinal correlates and demografic predictors of monetary beliefs and behaviours. Journal of Organizational Behavior, 17(4), 375-388.

Gouveia, V. V. (1998). La naturaleza de los valores descriptores del individualismo e del colectivismo: una comparación intra e intercultural. Tese de Doutorado. Departamento de Psicologia Social, Universidade Complutense de Madri, Espanha.
Gouveia, V. V., Fonseca, P. N., \& Milfont, T. L.; Fischer, R. (2011). Valores humanos: Contribuições e perspectivas teóricas. In C. V. Torres; E. R. Neiva (Eds.). A psicologia social: principais temas e vertentes. Porto Alegre: ArtMed.

Gouveia, V. V., Milfont, T. L., Fischer, R., \& Coelho, J. A. P. M. (2009). Teoria funcionalista dos valores humanos: Aplicações para organizações. Revista de Administração Mackenzie, 10, 34-59.

Gouveia, V. V., Milfont, T. L., Fischer, R., \& Santos, W. S. (2008). Teoria funcionalista dos valores humanos. In M. L. M. Teixeira (Ed.). Valores humanos e gestão: novas perspectivas (pp. 47-80). São Paulo: Senac.

Gouveia, V. V., Santos, W. S., Milfont, T. L., Fischer, R., Clemente, M., \& Espinosa, P. (2010). Teoría funcionalista de los valores humanos en España: comprobación de las hipótesis de contenido y estructura. Interamerican Journal of Psychology, 44, 203-214.

Gouveia, V. V., Vasconcelos, T. C., Queiroga, F., França, M. L. P., \& Oliveira, S. F. A. (2003). Dimensão social da responsabilidade pessoal. Psicologia em Estudo, 8(2), 123-131.

Gusmán, F. G. H. (2000). Dinero y psicología social: la dimensión simbólica de la moneda. In D. Caballero; M. T. Méndez; J. Pastor (Eds.). La mirada psicosocioógica: grupos, procesos, lenguajes y culturas. Madrid: Biblioteca Nueva.

Inglehart, R. (1977). The silent revolution: Changing values and political styles among Western publics. Princeton, NJ: Princeton University Press.

Krueger, D. (1986). The last taboo: Money as symbol and reality in psychoterapy and pshcyoanalysis. New York: Brunner Mazel.

Maslow, A. H. (1954). Motivation and personality. New York: Harper and Row.

Moreira, A. (2000). Valores e dinheiros: um estudo transcultural das relações entre prioridades de valores e significado do dinheiro para indivíduos. Tese de doutorado não publicada. Universidade de Brasília, Brasília.

Rinaldi, E., \& Giromini, E. (2001). Money socialization tracks and gender differences: A study on italian children. Paper apresentado no Congresso IAREP.

Rokeach, M. (1973). The nature of human values. New York: Free Press.

Ros, M. (2006). Psicologia social dos valores humanos: Uma perspectiva histórica. In M. Ros; V. V. Gouveia (Orgs.). Psicologia social dos valores humanos: desenvolvimentos teóricos, metodológicos e aplicados. São Paulo: Senac.

Schwartz, S. H. (1992). Universal in the content and structure of values: Theoretical advances and empirical tests in 20 countries. In M. P. Zanna (Ed.). Advanced in experimental social psychology. New York: Academic Press.

Super, C., \& Harkness, S. (1986). The developmental niche: a conceptualization at the interface of child and culture. International journal of development, 9, 545-569.

Tang, D. S. H. (1992). The meaning of money revisited. Journal of Organizational Behavior, 13(2), 197-202.

Távora, G. (2003). As relações entre significado do dinheiro e significado do salário para motoristas e cobradores de empresa de transporte público. Dissertação de Mestrado, Universidade Federal do Pará.

Thierry, H. (1992). Payment: Which meanings are rewarding? American behavioral scientist, 35(6), 694-707.

Van Der Geest, S. (1997). Money and respect: the changing value of old age in rural Ghana. África, 67(4), 535-559. 
Webley, P. (1983). Growing up in the modern economy. Paper apresentado no the $6^{\text {th }}$ International Conference on Political Psychology, Oxford.

Webley, P., \& Lea, S. E. G. (1993). The partial unacceptability of money in repayment for neighborly help. Human Relations, 46(1), 65-76.

Wernimont, P. F., \& Fitzpatrick, S. (1972). The meaning of money. Journal of Applied Psychology, 56, 218-226.

\section{Autores:}

Iani Dias Lauer-Leite - Doutora. Universidade Federal do Pará.

Celina Maria Colino Magalhães - Doutora. Universidade Federal do Pará.
Rildésia Silva Veloso Gouveia - Doutora. Centro Universitário de João Pessoa (Unipê).

Deliane Macedo Farias de Sousa - Doutora.Universidade Internacional da Paraíba. Patrícia Nunes da Fonseca - Doutora. Universidade Federal da Paraíba. Ana Karla Silva Soares - Doutoranda. Universidade Federal da Paraíba.

\section{Endereço para correspondência:}

Rildésia Silva Veloso Gouveia

Centro Universitário de João Pessoa (Unipê)

Departamento de Direito - Campus do UNIPÊ, Blocos C e E

BR 230 - Km 22 - Água Fria

CEP: 58053-000 João Pessoa, PB, Brasil

E-mail: rsvgouveia@gmail.com

Recebido em: 29.9.2012.

Aceito em: 11.11.2013 